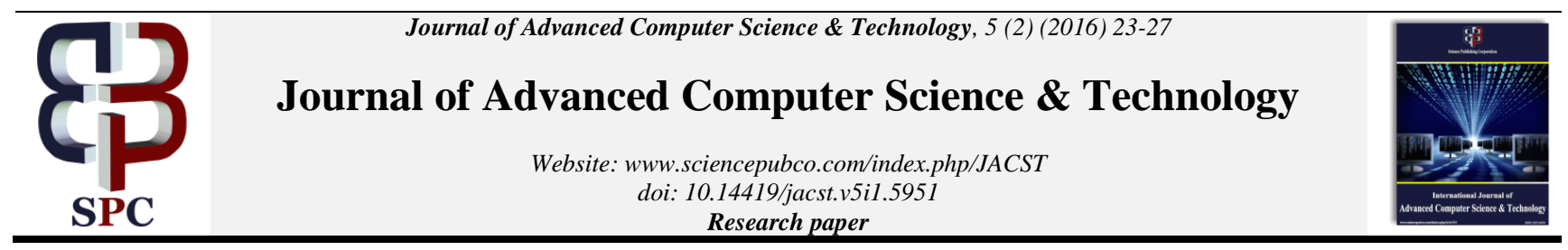

\title{
Managing a computer system and interface, performance and applications
}

\author{
Nderim Zeqiri * \\ State University in Tetova - Faculty of Applied Sciences (FSHZ)-Mechatronics 1200-Tetovo, R. Macedonia \\ *Corresponding author E-mail: nderimzeqiri@gmail.com
}

\begin{abstract}
Computer system has important command under various objects. To have a stable system, there is a need to create the model and functionality in terms of management and programming. The purpose of this paper is to present computer system as a central source, and other systems management interface for external management facilities. The logic of interaction of various objects is to create structures with universal purposes. In the paper presented the functioning of the computer system with microcontrollers and especially with Arduino Uno device. Also, is analyzed the performance of computer system, and are given the perspective and other question in the context of problem-solving. So, finally is given the comparisons with other systems.
\end{abstract}

Keywords: Computer System; Management; Arduino; Performance.

\section{Introduction}

Personal computer includes components of a computer system, which are designed according to the needs and requirements of users. The digital technology has changed the way when we use digital devices for interactive purposes. Digital devices are based on a series of binary numbers which is the way to process the information's and to gives the opportunity for other external devices to be connected and to manage about their data. The possibility of generating binary output outcome, offers us significant practical actions. Converting the decimal values in the binary values, as terminals representations, allow us to have access into various facilities. So, in the paper has been described the interconnection of hardware as devices and with software-solutions and systems. The software includes instructions for managing the computer system and the implementation of various applications. In the context of the methodology, will be used method of analysis, comparison, and empirical methods. Computer interconnection with other systems, allows us access to outdoor facilities and receiving information simultaneously [1], [2].

\section{Computer system, computer network and performance}

Computer system contains the necessary elements, as can be ranged: computers, connections, router, server, web server, etc. To have good communication, the equipment must be standardized and configured. However, according to the analysis, here can be study the computer systems (types $\mathrm{x}, \mathrm{y}$ and $\mathrm{z}$ ). In Figure1, is given this system [3], [4].

The aim of the system management is:

- Does the system would be effective?

- Why performance of system has important role and impact in this configuration?

The next table 1 described why the system is with better performance. The results are given as an inductive process of analyses. For example, firstly is needed to know, why is necessary, to be analyzed the differently tasks, and why the systems approximately must be with same configurations? The answer is very simple, because, this is the way to analyze their performance. The performance has in itself contexts the process, for evaluation, to evaluate the duration, to realize any task, any problem, or any process when total systems is loaded. This is the reason why to solve any specific question or tasks [5], [6]. For example, in the following table are presented these tasks and the time when the process is realized, so this time is so called, the duration.

Table 1: Computers Systems, Tasks and Durations

\begin{tabular}{llll}
\multicolumn{4}{c}{ Table 1: Computers Systems, Tasks and Durations } \\
\hline Tasks & Computer system_x & Computer system_y & Computer system_z \\
\hline T1=Task1 & $0.1 \mu \mathrm{s}$ & $0.15 \mu$ & $0.12 \mu \mathrm{s}$ \\
T2=Task 2 & $0.3 \mu \mathrm{s}$ & $0.25 \mu$ & $0.32 \mu \mathrm{s}$ \\
T3=Task3 & $0.4 \mu \mathrm{s}$ & $0.45 \mu$ & $0.42 \mu \mathrm{s}$ \\
T4=Task4 & $0.2 \mu \mathrm{s}$ & $0.15 \mu$ & $0.12 \mu \mathrm{s}$ \\
T5=Task5 & $0.1 \mu \mathrm{s}$ & $0.15 \mu$ & $0.2 \mu \mathrm{s}$ \\
$\ldots$ & $\ldots$ & $\ldots$ & $\ldots$
\end{tabular}




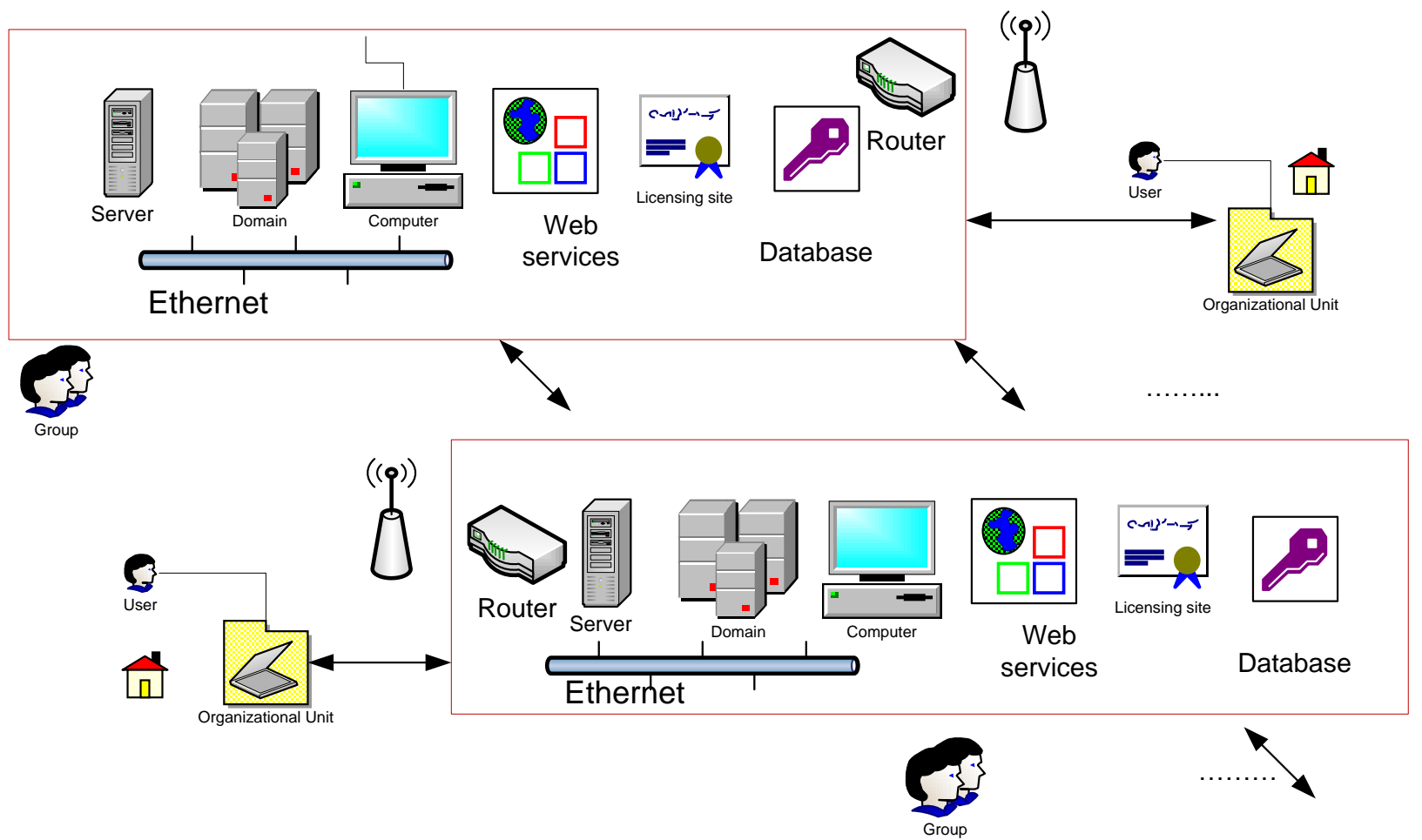

Fig. 1: Computer System and Intercommunication with another System.

$\mathrm{T}_{\mathrm{x}}=\mathrm{T}_{1 \mathrm{x}}+\mathrm{T}_{2 \mathrm{x}}+\mathrm{T}_{3 \mathrm{x}}+\mathrm{T}_{4 \mathrm{x}}=1.1 \mu \mathrm{s}$

$\mathrm{T}_{\mathrm{y}}=\mathrm{T}_{1 \mathrm{y}}+\mathrm{T}_{2 \mathrm{y}}+\mathrm{T}_{3 \mathrm{y}}+\mathrm{T}_{4 \mathrm{y}}=1.15 \mu \mathrm{s}$

$\mathrm{T}_{\mathrm{z}}=\mathrm{T}_{1 \mathrm{z}}+\mathrm{T}_{2 \mathrm{z}}+\mathrm{T}_{3 \mathrm{z}}+\mathrm{T}_{4 \mathrm{z}}=1.18 \mu \mathrm{s}$

According to equation (1) it appears that shorter duration has system - computer system $\mathrm{x}, \mathrm{T}_{\mathrm{x}}=1.1 \mu \mathrm{s}$.

Therefore, this system has greater performance.

$\mathrm{P}_{\mathrm{x}}=\frac{1}{\mathrm{~T}_{\mathrm{x}}}=0.909$

And lesser performance has system, computer system_z:

$\mathrm{P}_{\mathrm{z}}=\frac{1}{\mathrm{~T}_{\mathrm{z}}}=0.847$

In the form of inequality may be present, the order of performance:

$\mathrm{P}_{\mathrm{x}}>\mathrm{P}_{\mathrm{y}}>\mathrm{P}_{\mathrm{z}}$

Assessment and conclusion, computer system_x has better performance, although the structure is the same as with computer system_y, and computer system_z. This system has better performance due to:

- Better maintenance,

- Suitable environment,

- Smallest impact ambient temperatures,

- Better versions of applications installed,

- Chip is less exposed to noise, and has less impact on the external dust.

- More sophisticated programs and better security and

- Possibility of manufacturing its own computer system stability, etc.

\section{Computer system, external interface and accuracy}

To control through a computer system, and to have a better performance of the system, when the computer systems is interfaced with external interface, (let it be) for example Arduino, as the main issue is the establishment of the basic elements, such is:

- Verification,

- System stability,

- Efficiency assessments,

- Generation of adequate values,

- Applying best model,

- The most convenient programming code,

- The application of functions, and proper orders

- Upload the program from the computer system in arduino,

- Validation and verification work,

- System testing and evaluation.

In this regard, in the following will give the movement a certain angle position of a servomotor.

\section{Servo motor and generating current posi- tions}

In this project will be used a Display- $4 * 7$ segment-where will be presented the current state of the servomotor, all of this will be achieved through the Arduino's chip, Figure2.

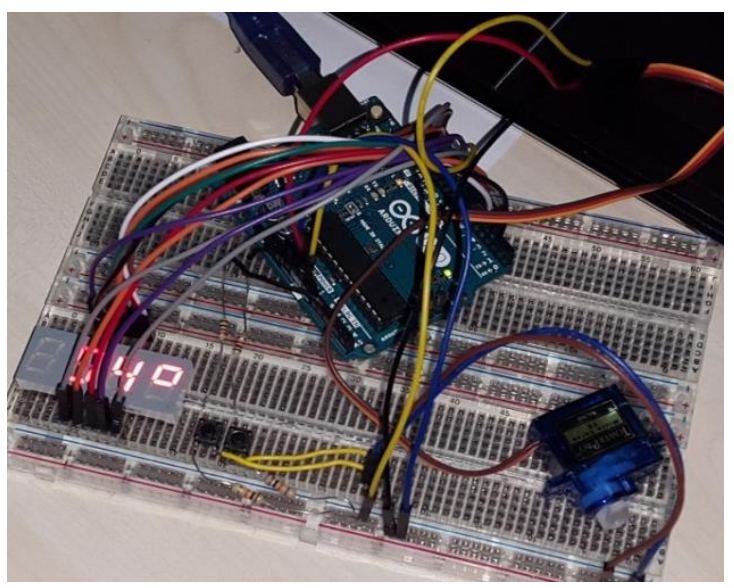




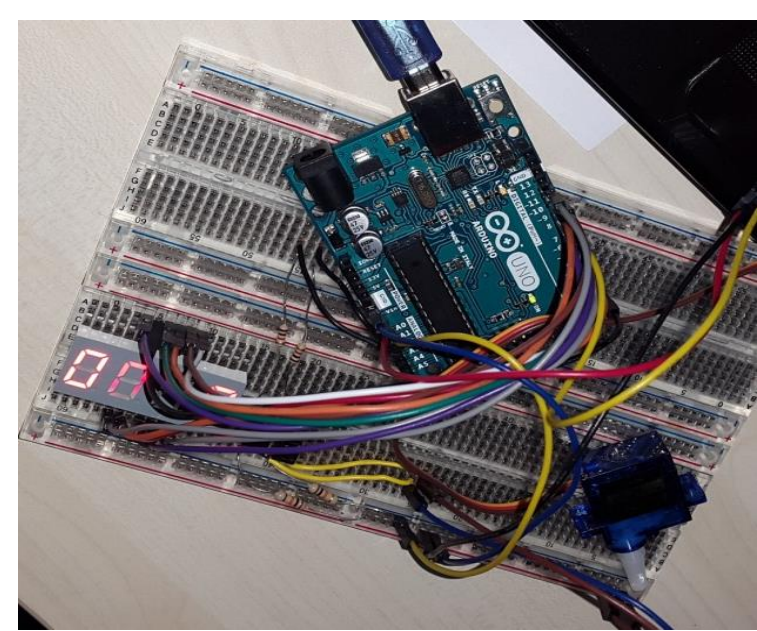

Fig. 2: The Position and Angle, Generation the Current Position through Servomotor.

Servo motor is position controlled motor. It can easily control physical movement of objects due to its position controlled feature. Servo motor cannot move continuously. Servo motors rotate in angel ranging from 0 to 180 degree. Servo motors have many applications in robotics and industry for position based motion control system. Unlike other motors, servo motor is very easy to interface with Arduino or any other microcontroller due to its built-in controllers.

The values presented in the Figure 2 , for example, " $54^{0}$ ", indicate the angle of the servomotor side position. This angle can be changed. This difference can be adjusted through several change in the program code, this step create the opportunity for another way and positions for servomotor [8],[9]. This angle changes, has a practical implementations, for the rotational moment of the arms, and this is a good choices' for servomotor control. This is important, because this system can be implemented in the:

- Robotic systems

- Digital control systems

- Positional designation systems

- The CAD/CAM system etc.

Based on analysis and evaluation, it was concluded that:

- The system (interface) is stable

- Is flexible

- Based on tasks performed, it has a high degree of credibility,

- It's possible to change the position in real time

- Programming code - is very flexible, can be generated and uploaded in arduino.

\section{Program code embedded in the system with Arduino interface}

In theory and practice, it is very important what the program code will be used. Program code, create the opportunity for the system to be developed and maintained. The good programming code is easier to manage.

\section{Computer systems}

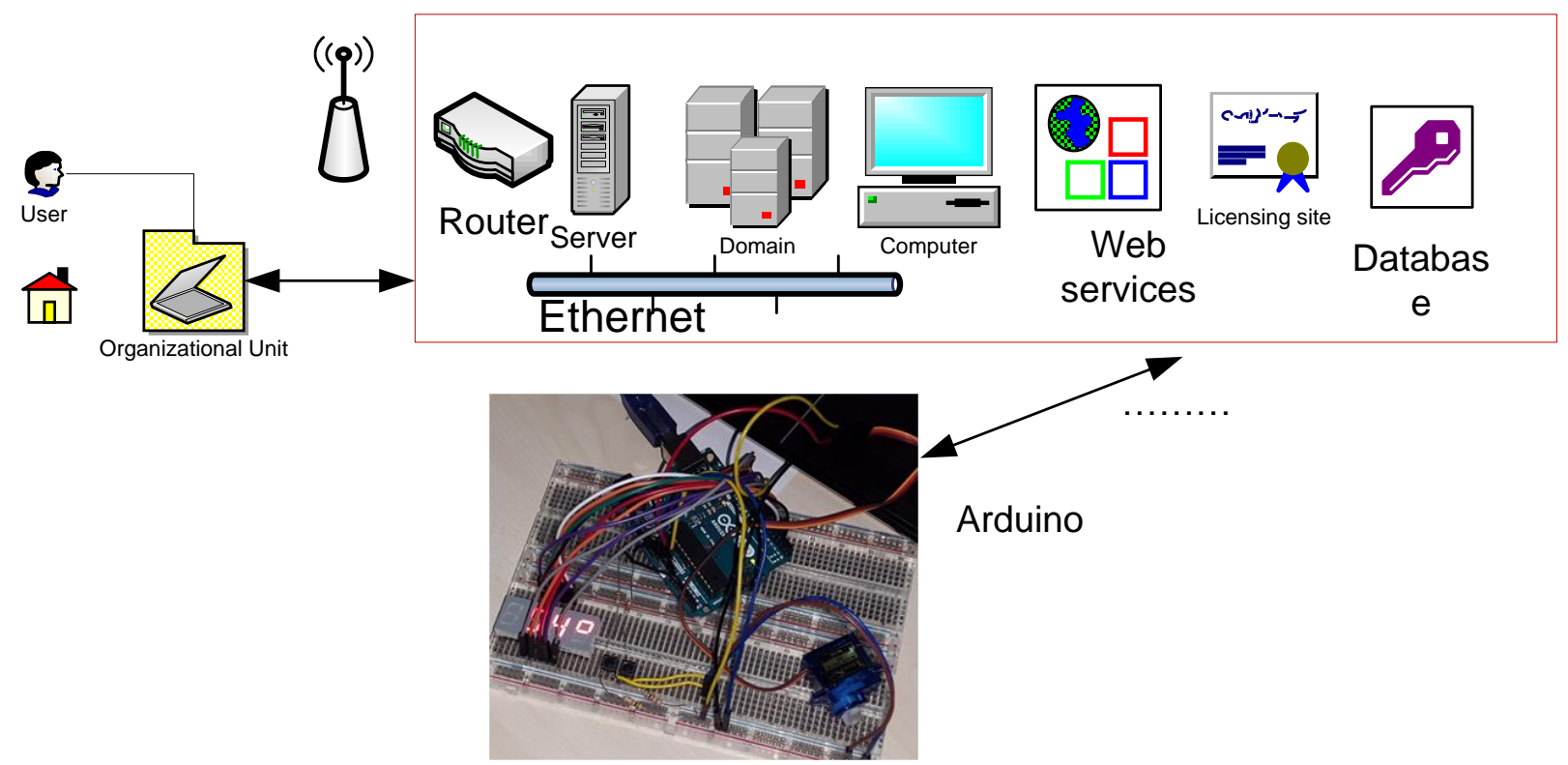

Fig. 3: Computer Systems and Arduino Interface.

The aspect of the code, is itself part of the software engineering [10], [11]. Where, in addition to a fixed computer structure, must be provided the program code, which should be:

- Convenient,

- Useful,

- Easy to manipulate,

- Assessed in real time,

- Adapted to working in differently environments and platforms,

- Maintained and

- To be updated

Program code:

\#include<Servo.h>

intaPin $=2 ; / / \mathrm{A}$
intbPin $=3$; //

intcPin $=4 ; / / \mid$

intdPin $=5 ; / /|\mathrm{F}| \mathrm{B}$

intePin $=6 ; / /|\mathrm{G}|$

intfPin $=7 ; / /$

intgPin $=8 ; / / \|$

int GND1 $=10 ; / / \mid$

int GND2 $=11 ; / /|\mathrm{E}| \mathrm{C}$

int GND3 = 12; //

int GND4 $=13 ; / / \mathrm{D}$

intnum;

int dig1;

int $\operatorname{dig} 2=0$

int $\operatorname{dig} 3=0$; 
int $\operatorname{dig} 4=0$;

intDTime $=4$;

intfUP $=\mathrm{A} 0$; //switch that tunes the frequency +0.1 at analog pin 0 . intfDOWN $=\mathrm{A} 1 ; / /$ switch that tunes the frequency -0.1 at analog pin 1.

intcount $=4$; / $/$ we use this counter as a placeholder to count how long a switch is pressed

intpos $=4$; / variable to store the servoposition

Servomyservo;

voidsetup()

\{

pinMode(aPin, OUTPUT);

pinMode(bPin, OUTPUT);

pinMode(cPin, OUTPUT);

pinMode(dPin, OUTPUT);

pinMode(ePin, OUTPUT);

pinMode(fPin, OUTPUT);

pinMode(gPin, OUTPUT);

pinMode(GND1, OUTPUT);

pinMode(GND2, OUTPUT);

pinMode(GND3, OUTPUT);

pinMode(GND4, OUTPUT);

myservo.attach(9);

Serial.begin(9600);

\}

voidloop()

\{

digitalWrite( GND1, HIGH);

digitalWrite( GND2, HIGH);

digitalWrite( GND3, HIGH);

digitalWrite( GND4, HIGH);

if $($ Serial.available ()$>0)$

\{

num $=$ Serial.parseInt () ;

pos = num;

Serial.print("\n");

Serial.print("Entered number: ");

Serial.print(num);

$\operatorname{dig} 1$ = num $/ 100$;

num $=$ num $-(\operatorname{dig} 1 * 100)$;

$\operatorname{dig} 2=$ num $/ 10$;

$\operatorname{dig} 3=$ num $-(\operatorname{dig} 2 * 10)$;

if $(\operatorname{pos}<=2)$

\{

Serial.print("'n");

Serial.println("TO SMALL");

\}

elseif $(\operatorname{pos}<=180)$

\{

Serial.print("'n");

Serial.print("Position: ");

Serial.print(pos);

\}

else

if(digitalRead(fUP)) //if frequency up switch is pressed and held, count increments

$\cdots$

voidpickNumber(int $\mathrm{x})\{$

$\operatorname{switch}(\mathrm{x})\{$

case 0: zero(); break;

case 1: one(); break;

case 2: two(); break;

case 3: three(); break;

case 5: five(); break;

case 6: six (); break;

case 7: seven(); break;

case 8: eight(); break;

case 9: nine(); break; default : four(); break;

\}

\}

\}

void $\mathrm{s}()$

\{

digitalWrite(aPin, $\mathrm{HIGH}$ );

digitalWrite(bPin, LOW);

digitalWrite(cPin, $\mathrm{HIGH}$ );

digitalWrite(dPin, HIGH);

digitalWrite(ePin, LOW);

digitalWrite(fPin, HIGH);

digitalWrite(gPin, $\mathrm{HIGH}$ );

\}

....

\section{Conclusions}

A servomotor is a rotary actuator that allows for precise control of angular position, velocity and acceleration. It consists of a suitable motor coupled to a sensor for position feedback. It also requires a relatively sophisticated controller, often a dedicated module designed specifically for use with servomotors.

Movement of objects can be controlled by controlling motion of motors. Similarly in robotics, servo motor control mechanism is very useful to control position of robotics.

Servo motors respond to change in duration of pulses. A pulse of duration 1 millisecond cause the servo motor to move one end and duration of 2 millisecond, cause the motor to move to other end. So we can calculate servo motor position by varying the duration of pulses to servo with the help of Arduino Uno. Arduino IDE have built-in library for servo motor control. So you don't need to write lengthy code for servo motor. You just have to call function used in servo.h library, as had been described in the above code.

- The Arduino microcontroller is an easy to use yet powerful single board computer that has gained considerable traction in the hobby and professional market. The Arduino is open source, which means hardware is reasonably priced and development software is free.

- The Arduino programming language is a simplified version of $\mathrm{C} / \mathrm{C}++$. If you know $\mathrm{C}$.

- Programming the Arduino will be familiar. If you do not know $\mathrm{C}$, no need to worry as only a few commands are needed to perform useful functions.

- A solder less breadboard is an essential tool for rapidly prototyping electronic circuits. Components and wire push into breadboard holes. Rows and columns of holes are internally connected to make connections easy.

- To interact with the outside world, the program sets digital pins to a high or low value using $\mathrm{C}$ code instructions, which corresponds to $+5 \mathrm{~V}$ or $0 \mathrm{~V}$ at the pin. The pin is connected to external interface electronics and then to the device being switched on and off.

- A computer program is a sequence of step-by-step instructions for the computer to follow. The computer will do exactly what you tell it to do, no more no less.

- All sequential programming languages have four categories of instructions.

- First are Operation commands that evaluate an expression, perform arithmetic, toggle states of I/O lines, and many other operations.

- Second are jump commands that cause the program to jump immediately to another part of the program that is tagged with a label. Jumps are one way to break out of the normal line-by-line processing mode. For example, if you want a program to repeat over and over without stopping, have the last line of the program is a jump command that takes the program back to its first line. 
- Third are branch commands that evaluate a condition and jump if the condition is true. For example, you might want to jump only if a number is greater than zero. Or, you might want to jump only if the state of an I/O line is low.

- $\quad$ Fourth are - Loop commands that repeat a section of code a specified number of times. For example, with a loop you can have a light flash on and off exactly six times.

- $\quad$ Functions are powerful programming features that are used when you want to set up an action that can be called from several places in the program.

\section{References}

[1] Martin Urban, Peter Bajcsy, Rob Kooperand Jean-Chistophe "Recognition of Arm Gestures Using Multiple orientation Sensors". Lementec2004 IEEE Intelligent Transportation Systems conference Washington, D.C., USA, October34,2004

[2] Seo, Y.H., Park, H.Y., Han, T., Yang, H.S.: Wearable Tele presence System using Multimodal Communication with Humanoid Robot. In: Proceedings of ICAT 2003. The Virtual

[3] Bruno Crispo, Melanie R.Rieback, Andrew S Tanenbaum a paper on "The Evolution of RFID security.

[4] Juels RFID security and privacy: A research survey IEEE Journal on chosen areas in Computing, 24(2): 381-394, February 2006.

[5] V. Subramanian, P. C. Chang, D. Huang, J. B. Lee, S. E. Molesa, D.R.Redinger, and S. K.Volkman, "Printed organic transistors for ultra-lowcost RFID applications", IEEE Transactions on Components and Packaging Technologies, 2005 http://dx.doi.org/10.1109/TCAPT.2005.859672.

[6] T. Phillips, T. Karygiannis, R. Kuhn, "Security Standards for the RFID Market".

[7] Burges J. (2008), "Is interactive 3D based multimedia more effective than 2D based multimedia in marketing"?

[8] Cironet, Inc. (2002), White paper on: "Wireless communications for industrial applications".

[9] Experian Marketing services, raport on: "The 2012 Digital Marketer: Brenchmark and Trend Report"

[10] Halsall F. (2001), "Multimedia Communications: Aplications, Networks, Protocols and Standards". 